\title{
Call to reduce junk food at checkouts
}

Y

ou pop by the hardware store on the way home from work to buy a screwdriver, not realizing you're feeling peckish until you see the snacks at the checkout counter. Sure, dinner is in an hour, but what's the harm in a candy bar (250 calories) and a bottle of soda (250 calories)? Well, those calories add up, and perhaps they shouldn't even be available in a place that sells hammers, according to the Center for Science in the Public Interest.

The ubiquity of food and beverages at checkout counters is a contributor to society's obesity problem, the centre states in a recent report, Sugar Overload: Retail Checkout Promotes Obesity. About $90 \%$ of the items available are unhealthy, the paper states, with candy accounting for $40 \%$ of offerings. And though supermarkets, supercentres and convenience stores offer more snacks at checkouts, there are still plenty of unhealthy options at stores that sell toys, clothing, home and bath supplies, hardware, books, electronics and sporting goods.

"There has been candy at supermarket checkouts for a long time, but what surprised us is how frequent you see candy and soda at checkouts of stores that aren't even in the business of selling food," says Jessica Almy, senior nutrition policy counsel for the centre and coauthor of the paper. "We were pretty hard-pressed to find any stores that didn't have food or soda at checkouts."

One of the major problems with food bought at checkouts is that they are impulse purchases, says Almy. Most shoppers had not planned to buy chocolate bars or soda or any other high-calorie snack and rarely factor them into their daily diet.

"The purchases at checkouts are additive," says Almy. "These are calories that people weren't planning on consuming, but they end up buying items and often consuming them right on site, and they have very little positive nutrition. These are not calories coming from bananas and apples and celery. These are calories coming from confectionary and soda and chips and snack cakes."

In the report, the Center for Science in the Public Interest recommends that non-food stores stop selling food and beverages at checkouts. It also recommends that food stores offer healthier foods at checkouts and adopt nutritional standards for items stocked near cash registers, including limits on calories, sodium and added sugars.

"We need to clean up the food environment the way environmentalists have been cleaning up our natural environment," says Almy. "We need to get rid of all of this pollution in our food environment, and the checkout is a good place to start. These are not foods people need, and they are not planned purchases. There is no reason that stuff needs to be there."

If change does happen, however, it will likely come through public policy or consumer pressure rather than voluntary actions by businesses, says Donald Lichtenstein, professor and chair of marketing at the Leeds School of Business, University of Colorado, Boulder. The role of a business in a market economy is to make money, not promote social good.

"If I'm the manager of a business, I'm evaluated on how much profit I turn back to the shareholders. So I'm going to do everything within the law to maximize profits. If something is not in the public interest, you can't ask me, as a business owner, to start adjusting my marketing variables or where I place products, because that's the role of the government," says Lichtenstein.

"The last entity I would look to is business. I would look to government and to consumers - consumers through education, and government through legislation."

Many businesses may in fact be exploring ways to boost sales of snack foods at checkouts. Increasing checkout purchases in "power categories," such as beverages and confectionary, by $1 \%$ could earn a store an extra US\$15 350 a year, according to a recent study, Optimizing Checkstand Merchandising. The study was produced by Front-End Focus, which promotes "best practices for superior checkout merchandising." Among its sponsors, according to its website, are Mars Chocolate and Coca-Cola.

The paper recommends that a store's "front-end focus" be on impulse-driven items, such as candy and carbonated soft drinks. Products to avoid selling at checkouts, the paper suggests, include health items, grocery products and nutrition/ energy bars. "The power categories of beverages, magazines and confectionary generate over $90 \%$ of front-end checkout sales," the paper states. "Merchandising the power categories on every lane is critical." - Roger Collier, CMAJ

CMAJ 2015. DOI:10.1503/cmaj.109-4940 